\title{
ECOLOGIA HUMANA: A NATUREZA ENQUANTO DIVINDADE ARQUETÍPICA
}

\author{
HUMANECOLOGY: THE NATURE AS AN ARCHETYPAL DIVINITY
}

\section{RESUMO}

O termo natureza, em sentido amplo, faz referência aos fenômenos do mundo físico e da vida em geral. Complexas são as suas definições, envolvendo qualidades de essencialidade, origem, espontaneidade e de tudo que não foi diretamente manipulado ouproduzidopelaaçãohumana, incluindooprópriouniverso. Levandoemconsideração que as ciências, em sua totalidade, se desenvolveram e têm se desenvolvido por meio de sua observação, o objetivo deste estudo é promover a cosmovisão da natureza enquanto fundamento para o autoconhecimento humano, uma vez que segundo a concepção da ecologia humana, os seres humanos são concebidos como parte indivisível de seu meio. Frente aos atuais enfretamentos ecológicos, a proposta justifica-se, sobretudo pela necessidade de reconexão do homem com a natureza em sentido superficial e profundo. Para tanto, utilizou-se do método de revisão teórica (especialmente em aportes conceituais de Arne Naess e Carl Gustav Jung) e do pensamento dedutivo aristotélico para alcançar as reflexões ecosóficas apresentadas. Os resultados sugerem o homem como ser indivisível da natureza, reinado por forças, tendências, instintos e ciclos similares aos do meio natural. A partir da contemplação natural, acredita-se possível formular compreensões profundas acerca da natureza humana, sejam elas, biológicas, psicológicas ou espirituais.

Palavras-chave: Ecologia Humana. Ecologia Profunda. Espiritualidade Matrifocal. Deusa Mãe.

\section{ABSTRACT}

The term nature, in a broad sense, refers to the phenomena of the physical world and life in general. Complex are their definitions, involving qualities of essentiality, origin, spontaneity, and everything that was not directly manipulated or produced by human action, including the universe itself. Taking into account that the sciences in their entirety have developed through their observation, the objective of this study is to promote the worldview of nature as a foundation for human self-knowledge, since according to the conception of human ecology, humans are conceived as an indivisible part of their environment. Faced with the current ecological constraints, the proposal is justified, above all, by the need to reconnect man with nature in a superficial and deep sense. For that, we used the theoretical revision method (especially conceptual contributions of Arne Naess and Carl Gustav Jung) and Aristotelian deductive thinking to reach the proposed reflections. The results suggest man as being indivisible from nature, reigned by forces, tendencies, instincts, and cycles similar to those of the natural environment. From natural contemplation it is believed possible to formulate deep understandings of human nature, be they biological, psychological or spiritual.

Keywords: Human Ecology. Deep Ecology. Matrifocal Spirituality. Mother Goddess.

Alisson José Oliveira Duarte

Universidade Federal do Triângulo Mineiro (UFTM). E-mail: alisson-duarte@hotmail.com 


\section{Natureza onipresente}

A mãe natureza é tudo, porque está em tudo, porque é tudo.

São as estrelas do céu, a lua, o sol, o cosmo e tudo que há no universo.

Água, terra, fogo e ar.

Passado, presente e futuro. É a energia que constitui a matéria.

A brisa, a bruma e o mar. É tudo aquilo que sustenta a vida. É a força pulsante em todas as coisas.

É a presa, é o predador É o bem, é o mal É a calmaria, é a tempestade É a mãe, é o pai É a vida, é a morte Começo, meio e fim.

Comemos a Deusa, vestimos a Deusa, Excretamos a Deusa no suor, nas fezes e na urina. A Grande Mãe é a melodia que se ouve no silêncio,

É o mais doce perfume e a mais fétida secreção. É tudo que há de mais asqueroso, horripilante e belo. Amamos e odiamos a Deusa. Somos a Deusa.

(HERMÍNIS, 2013)

A natureza é uma multiplicidade de formas, forças e mecanismos naturais. São infinitas as suas faces e múltiplas as suas manifestações. Ela é a própria diversidade que se interliga e se completa. Ninguém pode ser visto como algo separado dela e por essa razão, considera-se toda individualidade como natureza de potencial criativo e transformador da realidade onde vive e interage.

Mediante a complexidade do meio natural, o homem, sobretudo em tempos arcaicos, divinizava a natureza e os seus fenômenos porque dela angariava recursos para sua sobrevivência e fundamentos para os seus conhecimentos. No substrato psíquico humano, a natureza se corporificou sob a forma de diferentes deuses e deusas, com especial foco sob a imago feminina, nitidamente associada à origem da vida (JUNG, 200o). Não é por menos que diferentes estudiosos defendem que a expressão espiritual da antiguidade repousava sobre as bases do culto ao feminino, embora as deidades masculinas nunca tenham deixado de existir como filhos ou frutos de uma Deusa Mãe.

Oliveira (2005: o8), em seus estudos sobre espiritualidade feminista e neopaganismo, afirma que, diferentemente da concepção patriarcal, a figura de DeusPai transcendente e desincorporado da matéria e do mundo, "a Deusa tem um corpo 
que é o mundo físico: o céu, a terra, as águas e o submundo. Essa concepção do divino dispensa intermediações, a Deusa - a imanente - está em tudo eé tudo. Todas as coisas: das pedras às árvores passando pelos seres humanos são a Deusa", seus fenômenos e suas diversas formas de existir. Para a autora, a espiritualidade matrifocal supera o "dualismo criador x criatura - característico das religiões patriarcais" - concebendo a divindade "como algo que está dentro da matéria física, reforçando a importância da ecologia e do corpo".

Na presente perspectiva, a célebre composição de Seixas (1974) "Gita" alude nitidamente ao sentido de onipresença/imanência que ora se pretende expressar em relaçãoà natureza. O compositor, em diversas passagens de sua canção, inspirada pelas épicas escrituras sagradas do livro Bhagavad-Gita do hinduísmo, ressalta a divindade Krishna (consciência cósmica) como substância presente em todas as coisas: "eu sou a luz das estrelas, eu sou a cor do luar, eu sou as coisas da vida, eu sou o medo de amar. Eu sou o medo do fraco, a força da imaginação, o blefe do jogador, eu sou, eu fui, eu vou". - Das coisas secretas, sou o silêncio, e dos sábios sou a sabedoria (BHAGAVADGITA, 1995: 523). - O livro sagrado, bem como a música, ocupa-se integralmente ao ofício de explicar ou de aproximar-se de uma explicação para a natureza divina. Dirigindo-se, em primeira pessoa, a divindade mitológica conhecida como "Suprema Consciência", afirma-se mais próxima da experiência humana e da natureza do que se pode imaginar.

Evidentemente alude-se a um mito que, assim como todos os outros, revela, na concepção da psicologia analítica, verdades arquetípicas sobre a realidade psíquica do homem ancestral, bem como da natureza humana (DUARTE, 2017). É fato que o homem, desde os seus primórdios, tem registrado, em seu substrato psíquico, a crença ou a fantasia de que a natureza e seus fenômenos são povoados de forças, deuses e espíritos (JUNG, 2002; GLEISER, 1997). Animismo foi o termo utilizado pelos antropólogos para descrever a espiritualidade daqueles que acreditavam que espíritos viviam nos fenômenos naturais; também justifica a relação de integração e de sacralidade do homem primitivo com seu meio. Segundo esse conceito, nos primórdios da humanidade, o homem acreditava que os animais, as plantas, os rios, as montanhas, as estrelas, o sol e a lua detinham entidades ou deuses, os quais eram fundamentais apaziguar através de oferendas e sacrifícios rituais (GAARDER, et al. 2005).

$\mathrm{O}$ termo natureza provém da palavra latina natura que, em sentido amplo, faz referência aos fenômenos do mundo físico, abstrato e da vida em geral. Complexas são as suas definições, envolvendo qualidades de essencialidade, origem, instinto, espontaneidade, materialidade, abstratividade, tempo, espaço (incluindo o próprio universo), vida, funcionalidade e substancialidade (FERREIRA, 200o).

A natureza é todas as coisas e está em todas as coisas, em todos os tempos e lugares. É a terra, o sol, a lua, o fogo, o vento, a água, as árvores, os vermes, o grão de areia, o universo e todas as criaturas viventes, não viventes e minerais. É a força envolvida em todas as transformações do universo, a energia que faz crescer a erva, o mecanismo ordenador das estações e o equilíbrio dos ecossistemas. É o tempo e o espaço que ocupam o próprio espaço e tempo. Amplamente multifacetada, a natureza 
se revela em suas infinitas formas e manifestações, visíveis ou invisíveis, presentes ou distantes, vivas ou mortas. Isso sugere que, toda matéria morta carrega em si a possibilidade de ser convertida em energia e utilizada para a sustentação de outras vidas. - A natureza é a matéria morta em potência de vida. - A casca de fruta, o estrume, o corpo sem vida e toda matéria orgânica são fontes de fertilidade que a terra transforma em energia. A natureza recicla a morte e faz dela energia de vida.

Por outro lado, quando Seixas (1974) canta "você pensa em mim toda hora, me come, me cospe, me deixa", faz-se alusão à relação de dependência e descaso do homem em relação ao seu meio: come-se e bebe-se todos os dias a natureza, pensa-se nela quando reflete-se sobre a vida ou quando as pessoas se lembram de outras, e a deixam quando se esquecem de conhecer e cuidar da própria natureza, da saúde ou quando negligenciam a consideração bioética pelo próximo não humano (os rios, as matas, a água, o solo, o boi estressado em arena de rodeio, o peixe tirado da água inutilmente durante a pesca esportiva, o pássaro enjaulado, entre outros comportamentos). De acordo com Oliveira (2005: 8), "o simbolismo da Deusa implica na aceitação da materialidade e da corporeidade da vida como sagradas".

Por fim, entende-se que o verso "você me tem todo dia, mas não sabe se é bom ou ruim" (SEIXAS, 1974) traduz o sentimento ambivalente que muitas pessoas têm em relação à natureza. Amam-na e odeiam-na no colo de sua fartura ou na violência de suas tempestades. Aliás, faz parte do percurso natural de tudo que vive integrar a morte aos processos da vida, os prazeres aos desprazeres, o bem ao mal, o belo ao feio, o alegre ao triste. A natureza é tudo, e esse tudo é o que faz da vida "a vida".

Não importa onde se esteja, a natureza imanente se faz em todas as coisas: abaixo de todos os seres, entre eles, acima deles e intrinsecamente neles. A natureza é a força governante do universo, a energia vital e atemporal envolvida em todas as transformações da biosfera. Nela, não se demarca início e nem mesmo fim.

Não era para menos que os antigos concebiam o tempo de forma cíclica, e não linear (o dia e a noite, as estações do ano, os ciclos lunares, o ciclo menstrual, etc.). Esse modo de conceber o movimento natural contraria a razão e os processos históricos lineares de começo, meio e fim, pois, em meio à natureza, o término de um ciclo automaticamente sugere o início de outro (GLEISER, 1997; JUNG, 2008).

Com o advento da modernidade, o nível de desconexão do homem com a natureza tem cada vez mais crescido (LAYRARGUES, 2004). A maioria das pessoas se acredita totalmente fora dela, ao ponto de não ter consciência de que absolutamente tudo tem suas origens no colo e no seio da mãe terra: o carro, o ônibus, a bicicleta, as casas, os sapatos, as roupas, os alimentos e tudo que há no mundo. O papel vem da celulose, a gasolina e o plástico derivam do petróleo, os metais provêm dos minérios, os tecidos vêm do algodão e assim por diante. Não se conhece no mundo nenhuma criação genuinamente humana. O homem precisa buscar, nos recursos naturais, a matéria-prima para edificar suas invenções e suprir suas necessidades.

Por isso, não é preciso advogar que a natureza é a razão e a sustentação de tudo. Como seria possível viver ou ser sem a natureza? - Seria preciso despir-se de todas as roupas, deixar de respirar e de pisar sobre a terra. Devendo se abster de todo e qualquer 
alimento e de toda bebida, porque todas têm por origem a água. Igualmente seria necessário deixar de ser, pois todo ser, em si, é natureza singular. Essa é uma questão óbvia, mas ainda é comum encontrar barreiras, nas sociedades ocidentais quando se fala de natureza, como se o dito ofício fosse um ato romântico, utópico e, portanto não científico. Discorrer sobre fenômenos isolados da natureza, especialmente no campo da biologia, química e física, é visivelmente válido no discurso racionalista e positivista, no entanto, quando se trata de estudos voltados para a compreensão da natureza enquanto totalidade e especialmente em relação ao homem enquanto microecologia indivisível da complexidade biosférica e do próprio universo, os pesquisadores tendem a encontrar preconceitos que os taxam de metafóricos, religiosos ou místicos.

Mesmo diante da complexidade da natureza como fonte potencial de todo conhecimento sobre a existência, por que ainda assim o homem insiste em destruir seu maior patrimônio? Ou será exatamente o fato de tratar a natureza como patrimônio capitalista que tem gerado essa relaçãoantropocêntrica e superficial em relaçãoao meio ambiente? - Em seus estudos sobre o arquétipo da deusa mãe e suas manifestações nos tempos atuais, Oliveira (2005: 13) destaca que as espiritualidades neopagãs tem se mostrado fortes aliadas nos movimentos em defesa a preservação ecológica. Para ela, "se olharmos para muitos dos movimentos sociais contemporâneos - feminista, ecológico, pacifista, simplicidade voluntária, entre outros - perceberemos, em todos eles, a presença inspiradora de tradições muito antigas, nas quais a Mãe Terra era honrada".

Os ancestrais há milhares de anos, mantinham estreita conexão com a natureza. A Grande Mãe, a Deusa Mãe ou simplesmente a Mãe Natureza era reverenciada em todas as circunstâncias: nas manifestações da chuva, nas mudanças das estações, na observação do fluxo dos rios, nos mistérios das florestas e assim por diante (GLEISER, 1997; JUNG, 2000).

Nos tempos atuais, as pessoas acreditam que o mundo moderno não depende mais da natureza. Consideram-se, dentro de uma perspectiva positivista, seres mais complexos e ilusoriamente independentes de seu meio, não "celebram" mais a natureza e tampouco reconhecem o valor das coisas naturais. Isso se deve ao fato de as pessoas viverem em pequenas e grandes cidades, longe das paisagens verdejantes, gerando a ilusão de que o homem é algo separado da natureza. Mas, na realidade, apesar da escassez do verde, sobretudo nas grandes metrópoles, ninguém está distante da natureza onipresente que se respira, que se alimenta, que se veste e se manifesta por meio do sol, do vento e da chuva que reabastece as bacias fluviais e rega as plantações.

A percepção da natureza cíclica é perdida quando passamos a maior parte do tempo nos ecossistemas artificiais chamados de cidades. Nelas não vivenciamos os ciclos das plantas e da terra. Vivemos a ilusão vendida pelo marketing do instantâneo, nos supermercados e shoppings, onde tudo pode ser comprado com um cartão de crédito, a qualquer momento do dia ou em qualquer estação (LAYRARGUES, 2004: 149). 
A natureza perdeu seu valor porque as pessoas têm perdido contato com ela desde o exílio rural e o início da urbanização. O homem moderno deixou a chuva e outras manifestações naturais se tornarem "coisas corriqueiras" e sem valor. A maioria das pessoas perdeu a sensibilidade perante as manifestações naturais: O nascer do sol, os ciclos lunares, o desabrochar de uma flor, a relva que hoje se pisa e amanhã aparece outra vez erguida. Essas observações tão sutis falam da capacidade ou da incapacidade que o homem tem de reconhecer o fluxo da força natural em manutenção da vida. $\mathrm{O}$ mecanismo que ninguém vê, mas que está o tempo todo trabalhando ao redor de tudo.

É crítico pensar que as pessoas só perceberão a importância das manifestações naturais quando elas deixarem de ser "corriqueiras" para se tornarem "raras". - A chuva cai, o sol evapora a água. Novamente a chuva cai e o sol evapora a água. Quem nunca presenciou esse ciclo comum? Porém, quando a chuva cair, o sol evaporar a água e a chuva demorar a cair outra vez, as pessoas perceberão o valor daquilo que acreditavam ser fenômeno meramente ordinário.

Oliveira (2005) sustenta que o principio feminino ligada à natureza e à espiritualidade matrifocal, carrega, em si, o potencial de reconciliação entre a humanidade e a natureza, interna e externa, e não somente em relação ao papel social da mulher. Para a autora:

A tarefa colocada para todos - mulheres e homens que se reconhecem como filhos da Grande Mãe - é a de subverter a direção da evolução cultural que predominou nos últimos anos e reformar a cultura em todos os seus aspectos, não apenas no campo das relações de gênero. É preciso repensar profundamente os valores sobre os quais se erigiu uma cultura violenta, consumista, predatória e mercantilizada que reduziu a natureza a uma matéria inerte e passiva e, cada vez mais, limita as trocas entre os seres humanos àquelas mediadas pelo mercado (OLIVEIRA, 2005: 13).

A exploração da natureza como objeto de manipulação do homem, em muito, reflete a exploração da mulher nas diferentes sociedades. A começar pelo mito cristão e seu dogma da trindade que excluiu (ou quis excluir) a figura feminina da sacralidade. Jung (2006) refere-se à mulher como o elemento oculto da trindade, claramente associado à imagem do mal (a escuridão do útero, ao diabólico) e à natureza (o pecado e a materialidade). Percebe-se que a mesma perspectiva excludente que relegou o papel social da mulher, desvalorizou a materialidade natural da vida terrena em prol de promessas de uma vida imaterial (no paraíso ou além-túmulo).

A humanidade precisa, outra vez, restabelecer as ligações perdidas com a Mãe Terra e se lembrar de que a existência humana depende invariavelmente da existência dela. Por mais que não se deseje admitir, a humanidade é tão dependente da natureza quanto foram seus ancestrais.

Para tanto, utilizou-se do pensamento dedutivo aristotélico, apresentado por Gil (2008) para inferir, a partir das premissas apresentadas, que a compreensão da 
complexidade humana deve, sob essa concepção, advir de um pensamento capaz de reconhecer o homem enquanto ser indivisível da natureza e potencialmente reinado pelas mesmas leis. Considera-se a ecologia humana a única ciência capaz de reintegrar o homem a suas raízes e às verdades sobre si mesmo.

\section{Ecorreflexões para o autoconhecimento}

Refletir a natureza é refletir a vida em todos os sentidos. Nada parece mais profundo e abrangente a se pensar. Nela, acredita-se residirem todas as respostas para todas as perguntas. A natureza abriga mistérios que possivelmente nunca serão indagados e, que nunca serão compreendidos pela razão ou por qualquer outra função psicológica dos seres humanos. Consideram-na um fenômeno inesgotável e sendo o homem parte indivisível de sua totalidade, é dedutível que o homem enquanto natureza somente pode ser compreendido integralmente a partir das mesmas leis, ciclos e fenômenos.

Conforme Jung (2008: 167), “a ciência termina nas fronteiras da lógica, o que não ocorre com a natureza, que floresce onde teoria alguma jamais penetrou. $A$ venerabilis natura não para no antagonismo, mas serve-se do mesmo para formar um novo nascimento".

A conexão com a natureza, em todos os seus aspectos, pode levar as pessoas à vivência de experiências tão profundas que dificilmente seriam descritíveis, isso porque a descrição cabe aos mecanismos da lógica. Tal experiência, muitas vezes, não se alcança por vias racionais, e sim por vias pouco conhecidas pelo espírito. De toda forma, em um esforço de descrição, considera-se o ato de conexão com a natureza uma experiência de "integração com o divino". Vivenciá-la em sua totalidade requer cientificar-se de sua amplitude e, acima de tudo, é preciso sensibilidade para sentila em sua simplicidade. O homem do campo, a despeito de muitos intelectuais, frequentemente vivencia a experiência de conexão com seu meio sem auxílio de sistemas filosóficos, sua própria história favorece uma íntima ligação com a terra e com todos os seres à sua volta. Para Jung (1988: 39), "quanto mais o homem conseguiu dominar a natureza, mais lhe subiu à cabeça o orgulho de seu saber e poder, e mais profundo tornou o seu desprezo por tudo que é apenas natural e casual”.

Ao homem moderno, é sugerido o ato de reflexão como mecanismo cognitivo capaz de favorecer em alguns indivíduos o despertar de uma conexão profunda com todos os seres do mundo, bem como uma religação com centro da própria originalidade. Conforme Pordage (1699) apud Jung (2008: 160), “a pura natureza está dentro de vós. E se conhecerdes a pura natureza, que é vosso verdadeiro ser, liberto de todo egoísmo perverso, então conhecereis a Deus; pois a divindade está oculta dentro da pura natureza, tal como a noz no envoltório da casca”. Jung (2007) concebia a imagem arquetípica de Deus como representação psíquica arcaica do Si-mesmo ou Self. A expressão "Deus" vem nesse contexto como possibilidade máxima de 
autorrealização que se dá à medida que o indivíduo se reintegra com todos os aspectos de sua personalidade. "A ideia de Deus faz parte do substrato último e inarredável da alma humana" (JUNG, 2007: 231), "como valor máximo e dominante supremo na hierarquia psíquica, está imediatamente relacionada com o Self ou é idêntica a ele" (JUNG, 2009: 150).

De acordo com Jung (1988: 3), frequentemente as pessoas confundem "autoconhecimento com conhecimento da personalidade consciente do eu". Para ele não se pode conhecer a si mesmo sem descer às profundezas do inconsciente onde reside in natura as bases do verdadeiro "eu”. Aliás, segundo suas concepções teóricas, o inconsciente "seria uma espécie de órgão natural sujeito às mesmas leis que regem o meio ambiente" (DUARTE, 2017: 21-22). Foi pioneiro em afirmar que o fundo da psique humana é natureza que não se deturpa sem graves prejuízos a personalidade dos indivíduos. No entanto, antes de alcançar esse estado de autoconhecimento e realização da personalidade (por meio da integração do arquétipo self as estruturas da consciência) o indivíduo vivencia máscaras, induzidas pelas exigências sociais, que nem sempre condizem com a realidade intrínseca da originalidade do ser ou de seu processo de autorrealização.

Se por um lado é difícil para o homem relegar sua originalidade, comportandose conforme os ideários e padrões socioculturais, igualmente é massacrante a ameaça de isolamento social. Para se defender de tal ameaça, os seres humanos ao longo das eras evolutivas desenvolveram um mecanismo de adaptação social que Jung (2011: 47) chamou de persona (máscara), com a qual os indivíduos podem camuflar aspectos de sua identidade e exercer diferentes papéis sociais. Para ele, a persona "representa um compromisso entre o indivíduo e a sociedade, acerca daquilo que alguém parece ser: nome, título, ocupação (...) tais dados são reais, mas em relação à individualidade essencial da pessoa, representam algo de secundário”. Mais adiante, na mesma obra, acrescenta utilizando-se de pensamento ecosófico:

A persona é um complicado sistema de relação entre consciência individual e a sociedade; é uma espécie de máscara destinada, por um lado, a produzir um determinado efeito sobre os outros e, por outro lado, a ocultar a verdadeira natureza do indivíduo (JUNG, 2011: 82).

As reflexões sugerem que as pessoas enquanto crescem são educadas a deixarem de ser o que são. Reconquistar a natureza perdida, o verdadeiro eu fragmentado da personalidade consciente é uma meta que, possivelmente, nem todos conseguirão alcançar no percurso da vida. Há pessoas que foram tão bem "adestradas" que jamais se aproximarão outra vez de suas raízes.

O modelo de reflexão que floresce neste estudo sugere a compreensão dos fenômenos naturaiscomoaportesfundamentaisemumajornadadeautoconhecimento, tornando-se substancial que os indivíduos se reconheçam enquanto natureza indivisível das diferentes redes ecológicas que compõem a biosfera terrestre. 


\section{O homem e sua desconexão com a natureza}

Se porventura aplicassem um questionário aberto às pessoas das diferentes sociedades do globo terrestre acerca da organização mais rica que elas conhecessem, certamente, ter-se-ia, por resultado, um conjunto restrito e massivo de empresas multinacionais do ramo alimentício, automotivo e tecnológico. Os dados hipotéticos poderiam servir de reflexão em torno de como as pessoas têm se esquecido de que a natureza é a maior de todas as organizações, sendo as demais, tão somente espelhos de sua harmonia funcional. A natureza é a fábrica de vida mais bem-sucedida que se pode conhecer; nada se compara em organização. Seus ciclos funcionam de forma sistêmica, e todos os seus mecanismos se entrelaçam perfeitamente. Pode-se viver sem as multinacionais, mas não sem os frutos colhidos do leito natural.

Na sede pela independência, o avanço tecnológico e a urbanização conseguiram ilusoriamente afastar o homem de suas raízes e de sua conexão com a Mãe Terra. Fato que não tem gerado somente danos ao meio ambiente, mas à própria vida psíquica do homem moderno. "Assim como identificamos processos ecológicos externos, podemos falar de uma ecologia da interioridade humana. A crise ambiental reflete o estado da psique do homem" (DUARTE, 2017: 17). De acordo com Jung (2012: 30), as neuroses surgem com o processo de domesticação social. Para ele, "o neurótico é apenas um caso específico de pessoa humana tentando conciliar dentro de si natureza e cultura".

A cisão do homem com a natureza representa essencialmente uma cisão consigo mesmo, uma vez que todo conhecimento humano concentra-se nas observações que o homem faz de seu meio.

Frente à necessidade imperial de reconexão do homem com seu meio, o filósofo e ecologista norueguês Arne Naess (1912-2009), precursor do movimento de Ecologia Profunda, propôs alterações culturais, políticas, sociais e econômicas como ações básicas para se alcançar uma convivência harmoniosa entre os seres humanos e a natureza (NAESS, 2001). A própria história do autor sugere íntima ligação com o meio ambiente. De acordo com Zimmerman (1992: 1) Naess, quando jovem, experimentou um profundo sentimento de identificação com todos os tipos de seres que, "como ele, de alguma forma também estavam se esforçando para realizar o seu próprio potencial".

De acordo com Naess (1973: 95), atualmente, tem-se usado o termo preservação ecológica em um nível superficial, segundo o qual o meio ambiente deve ser preservado devido à sua importância para a sobrevivência humana, e não porque o homem realmente se importa com a natureza e tampouco com os demais seres que dela dependem. Sem retirar a sua relevância, o autor chama esse movimento de Ecologia Superficial, que tem por principal foco a luta contra o esgotamento dos recursos naturais. No entanto, observa-se que esse modelo de preservação ecológica, embora importante, tem caráter egocêntrico, uma vez que defende a natureza pelo seu valor enquanto recurso de exploração, não levando em consideração o homem e o meio ambiente como organismos inseparáveis. 
Naess (1992) amplifica o sentido convencional de ecologia, expressando conceitosquetranscendem oquese espera dos movimentosambientalistas tradicionais. Segundo ele "o movimento de ecologia profunda tem por objetivo geral participar na superação da crise ecológica. Seus defensores têm em comum o sentimento intrínseco de valorização do direito de viver e florescer de todo ser vivo independente de espécie" (NAESS, 1992: 2). Tradução do autor. Para ele:

O ecologista desse movimento adquire um profundo respeito, e até mesmo veneração pelos diferentes modos de vida. Alcançando uma compreensão interior, um tipo de ética que usualmente as pessoas reservam apenas para os membros da raça humana ou para grupos restritos de vida. Para o ecólogo profundo o direito de viver e desabrochar torna-se igual para todos os seres, sendo esse, um valor axiomático, intuitivamente claro e óbvio (NAESS, 1973: 95-96). Tradução do autor.

O modelo de Ecologia Profunda de Naess (2001) leva à reflexão da necessidade de colocar cada um dos processos econômicos e sociais a serviço da vida, e não a vida a serviço deles. O que se espera desse movimento é o nascimento de uma nova relação entre o homem e a natureza enquanto partes indivisíveis de um todo.

Como não poderia ser diferente, o presente estudo promove a reconexão do homem com a natureza enquanto fonte de conhecimentos sobre a vida, o mundo, o universo e si mesmo. Mas é fundamental nesse processo que o homem relegue seu antropocentrismo e se coloque na posição de mais um ser da natureza, não mais importante do que qualquer outro. É preciso cientificar-se de que a natureza não está a serviço da humanidade, nela pulsa vida que não pertence exclusivamente ao homem.

Para tanto, a ecologia humana, a ecologia profunda e outros meios ecosóficos de reflexão são ressaltadas como recursos educativos e de autoconscientização capazes de nutrir a possibilidade de um novo modelo de homem: maduro e consciente de si mesmo e do mundo à sua volta; capaz de assumir suas fragilidades e reconhecer suas potencialidades; capaz de fazer-se e refazer-se no contato com suas reservas criativas; ciente de sua liberdade e de suas responsabilidades enquanto sujeito ativo no movimento da vida; um ser humano apto a reconhecer sua singularidade sem se esquecer, no entanto, de suas raízes; um homem que é homem, mas que também é bicho; humanos cidadãos do mundo.

Este estudo celebra a natureza do começo ao fim. Busca-se, por meio dele, promover novos sentidos e conexões de vida. Todavia, convém esclarecer que esse material, por si, não basta para que se tenha uma compreensão profunda da natureza. A mater natura deve, acima de tudo ser sentida e não racionalizada; se não houver o mínimo de sensibilidade para apreciá-la, não serão exclusivamente os sistemas ecosóficos que darão sentido intrínseco de conexão aos indivíduos, assim como declarou Jung (2002: 117): chega-se à natureza não mediante a razão, "mas por sua experiência". 


\section{Raízes históricas do culto à mãe natureza}

Antes do advento do corpo de saberes que hoje se conhece por ciência, a relação do homem antigo com seu meio era completamente diferente. A natureza era respeitada e reverenciada como fonte de sobrevivência e de todo conhecimento sobre os mistérios da vida (GLEISER, 1997).

De acordo com Jung (2002), entre os primitivos, havia uma fusão entre os conceitos de natureza e divindade, tudo ao seu redor se associava a um acontecimento anímico. A natureza era para o homem antigo a própria presença divina e o palco de suas manifestações. A lua, o sol, as estrelas, os animais, a terra, o fogo, a água, o ar, as florestas e os bosques foram mitologizados e cultuados pelos ancestrais. A relação do homem com a natureza era de extremo respeito, pois se tratava de uma relação com a própria divindade.

Basta um olhar sobre as antigas mitologias para ver que em grande parte os deuses personificavam fenômenos naturais. Entre os gregos e romanos, Apolo era o Deus Sol, Deméter, a Deusa da fertilidade da terra, Pandora, a Deusa das árvores, Gaia, a mãe terra, enquanto Zeus associava-se ao trovão (BULFINCH, 2006). Não longe da realidade brasileira, é o que também se pode observar no Candomblé, segundo o qual cada Orixá (divindade) representa uma força da natureza: Oxum (representa os rios e cachoeiras); Iansã (os ventos); Oxossi (as matas); Iemanjá (os oceanos), eassim por diante.

Jung (2000: 87) afirma que "o conceito de Grande Mãe provém da história das religiões", fato que provavelmente sugere que o culto à natureza seja a base de toda religião antiga. Não se faz referência nessa citação unicamente às sociedades matriarcais ou matrifocais. De acordo com Neumann (1999: 49), independentemente da sociedade, o simbolismo da Grande Mãe é uma realidade psicológica atemporal, cuja imagem ainda sobrevive "no âmago do homem moderno".

Entre alguns primitivos, esse Grande Materno tomava status e assumia traços de grandeza e sabedoria por se tratar da mãe que estava acima de todas as mães, a criadora das criadoras, a Mãe Terra, provedora e sustentadora de todos os filhos. Em seu aspecto negativo se manifesta pela imagem da mãe privativa (a seca) ou por meio da mãe punitiva (tempestade, terremotos e outros fenômenos naturais violentos) (JUNG, 2002).

Se por um lado, o homem primitivo celebrava ritos e sacrifícios a fim deapaziguar as forças da natureza, por outro, reconhecia que a natureza, ao mesmo tempo em que "punia", também alimentava. A natureza, para o homem primitivo, era vista como o grande seio no qual a humanidade se alimentava e supria todas as suas necessidades, fato esse que, provavelmente, levou a associá-la à figura materna. De acordo com Jung (2008: 29), a palavra "mãe":

Refere-se aparentemente à mãe mais conhecida de todas, à nossa mãe individual, mas enquanto símbolo, "minha mãe" designa algo que no fundo se opõe obstinadamente à formulação conceitual, algo que se poderia definir vagamente e intuitivamente como a vida do corpo, oculta e natural (...) "Mãe" é um arquétipo que 
indica origem, natureza, o procriador passivo (logo, matéria, substância) e, portanto a natureza material, o ventre (útero) e as funções vegetativas e, por conseguinte também o inconsciente, o instinto e o natural, a coisa fisiológica, o corpo no qual habitamos ou somos contidos.

$\mathrm{O}$ autor alude à imagem materna como arquétipo universal que transcende a imagem familiarde mãe, referindo-sea algo deproporções maiores, a mãecoletiva, criadora de todas as coisas, que também simboliza tudo aquilo que é natural nos indivíduos.

Basta observar como as pessoas tendem a divinizar inconscientemente a natureza, por exemplo, diante de catástrofes naturais para ver que o culto à natureza sempre existiu nas profundezas da alma humana. Não raras vezes, é possível depararse, no cotidiano, com citações como: "estamos sofrendo a vingança da natureza"? Afinal, a natureza se vinga de alguém? É uma entidade? A crença de que a natureza pode se virar contra a humanidade é uma ideia antiquíssima e tem suas origens no medo do homem primitivo frente aos fenômenos naturais.

Convém lembrar que a relação do homem primitivo com a natureza se estendia para além das funções imediatas de bem-estar e segurança do grupo, abrangia também necessidades de ordem metafísica, nas explicações da morte, dos ciclos da vida e das questões existenciais de uma forma geral (GLEISER, 1997).

Depois do advento do cristianismo, todas as religiões antigas foram classificadas sob o termo de paganismo. Esse foi um termo genérico amplamente difundido para designar as religiões primitivas e dos bárbaros, bem como qualquer outro sistema religioso que não tivesse por base pressupostos do cristianismo, especialmente o batismo, a pedra basilar da referida religião, com o qual a Igreja define a condição do indivíduo enquanto cristão ou pagão (FERREIRA, 200o).

Munidos de uma cosmovisão laica, independente de ideologias religiosas ou não religiosas (ateístas), considera-se nesse estudo o modo pagão de pensar e de se relacionar com a natureza, a perspectiva que melhor poderá contribuir com o processo dereintegraçãodohomem com seu meio. Embora primitiva erepletadefantasias do homem antigo (antes, obscurecido pela limitação de conhecimentos), é possível reconhecer, em meio à sua simplicidade, um valioso sentimento de conexão com as complexidades da vida. - A natureza inspira o homem a buscar respostas que reside nela mesma.

Defende-se que, na modernidade, o exercício desse sentimento arcaico perante a natureza, adjunto aos avanços científicos e tecnológicos, poderá contribuir com o florescer de uma perspectiva renovada e profunda no campo da bioética. Não objetiva de forma alguma a reformulação de religiões arcaicas, tampouco a formulação de uma nova, mas sim promover a reconexão do homem com seu meio e, consequentemente, com os seus processos intrínsecos. Isto é, promovendo a conscientização sobre si mesmo enquanto ser reinado por processos similares aos sistemas ecológicos: criação/ criatividade, regeneração, renascimento, padrões/coletividade, singularidade, instintos, ciclos, diversidade, reciclagem, homeostase e transformação que não pertencem somente aos fenômenos externos, mas também à interioridade humana. 


\section{Considerações finais}

Todo ser, por excelência, é natureza e, se a ciência porventura pudesse provar empiricamente a existência de deus, ela certamente se ocuparia em estudar e investigar sua profunda natureza. O ser de uma pedra se explica pela sua formação maciça, inanimada, mineral e, sobretudo, por sua história secular que não sofreu em absoluto as mesmas ações que suas semelhantes. Embora conserve aspectos coletivos de sua espécie, o ser de qualquer pedra é único. A pedra não é somente um ser, mas também um microuniverso que abriga, em sua superfície, milhões de outros seres (microscópicos). Assim, ressoa a complexidade humana, com seus atributos coletivos dentro da própria espécie, com suas marcas de singularidade e suas intersecções comportamentais e funcionais com todos os outros seres fora de sua espécie.

O homem chama de ciência a coleção de saberes que ele adquiriu através da observação do meio ambiente, de si mesmo e do universo. Mas o homem tornou-se orgulhoso com o pouco que aprendeu e tem usado o saber da natureza de maneira não sábia. Atualmente, não se pode falar de progresso científico e tecnológico se esse não estiver em conexão com a vida, caso contrário, é falso progresso.

O verdadeiro progresso deve oferecer a possibilidade de sobrevivência de toda biosfera terrestre. $\mathrm{O}$ avanço tecnológico e tudo que o homem vem chamando de desenvolvimento têm levado à falência da raça humana e de toda existência. É o que se pode chamar de um progresso para morte, um suicídio em massa da humanidade e um atentado contra a vida das demais espécies que lutam pela sobrevivência. Por outro lado, o desenvolvimento para a vida é aquele que permanece em conexão com o fluxo ecológico, e nunca contra ele.

Se o homem insistir no atual modelo de progresso de morte, de exploração e de desconexão com a natureza, o planeta possivelmente rumará à destruição. A esse respeito, os ancestrais, há milhares de anos, já sabiam que a perpetuação da espécie humana, bem como da vida, dependeria do relacionamento do homem com a natureza. Nessa perspectiva, defende-se que o modo pagão de pensar, de sentir e de respeitar a natureza serão os únicos meios de livrar a humanidade da destruição planetária e da dizimação da vida terrestre.

Dificilmente alguém poderá contestar a evidência de que a natureza rodeia todos os indivíduos de modo onipresente no chão que se pisa, nos alimentos e líquidos que se ingerem, no ar que se respira, nos instintos e tendências psicológicas; no sol que aquece, na lua, nas estrelas, no mar e assim por diante. O conceito de natureza é profundamente amplo, abrangendo tanto aspectos masculinos/femininos, materiais/ abstratos, bons/maus, cognitivos/incognoscíveis, entre outros pares de opostos.

O estudo da natureza enquanto fonte para o autoconhecimento humano não configura misticismo, não sendo necessário que ateus setornem religiosose, tampouco, que religiosos abandonem a sua cosmovisão espiritual. As percepções acerca da natureza podem se adaptar a todas as diversidades de pensamento, exatamente por não se tratar de uma crença religiosa, mas de um modo ecosófico de reflexão. 
Para o homem existir, não basta viver, é preciso aprofundar na vida. E sendo a natureza a sua fonte original, é preciso pensá-la, recriá-la e senti-la para realmente sentir-se em conexão com a vida e com a própria originalidade. O sentido de preservação ecológica que floresce neste estudo busca conquistar mais que o interesse da espécie humana de garantir a integridade dos recursos de exploração. Visa alcançar, acima de tudo, uma profunda ética por todos os seres, independente de espécie. Para tanto, é proposta a essência da espiritualidade pagã e matrifocal como forma de resgatar a natureza perdida e de viver em consonância com a mãe terra.

\section{Referências}

BHAGAVAD-GITA. PRABHUPADA, Bhaktivedanta Swami. (1995). Bhagavad-Gita: Como ele é. Lisboa: The Bhaktivedanta Book Trust Internacional.

BULFINCH, Thomas. (2006). O livro da mitologia: História de deuses e heróis. São Paulo: Martin Claret.

DUARTE, Alisson José Oliveira. (2017). "Ecologia da alma: a natureza na obra científica de Carl Gustav Jung”. Junguiana, São Paulo, v. 35, n. 1: p. 05-19, jun/jul.

FERREIRA, Aurélio Buarque de Holanda. (2000). Miniaurélio Século XXI Escolar: O minidicionário da língua portuguesa. Rio de Janeiro: Nova Fronteira.

GAARDER, Jostein; et al. (2005). O livro das religiões. São Paulo: Companhia das Letras.

GIL, Antonio Carlos. (2008). Métodos e técnicas de pesquisa social. São Paulo: Atlas.

GLEISER, Marcelo. (1997). A dança do universo: dos mitos de criação ao Big Bang. São Paulo: Companhia das Letras.

JUNG, Carl Gustav. (2000). Os arquétipos e o inconsciente coletivo. Petrópolis: Vozes. . (2002). Estudos Alquímicos. Petrópolis: Vozes. . (2006). Interpretação Psicológica do Dogma da Trindade. Petrópolis: Vozes. . (2007). A natureza da psique. Petrópolis: Vozes. . (2008). Ab-reação, análise dos sonhos, transferência. Petrópolis: Vozes. (2009). Aion: Estudos sobre o simbolismo do Si-mesmo. Petrópolis: Vozes. 
(2011). O Eu e o inconsciente. Petrópolis: Vozes.

(2012). Psicologia do Inconsciente. Petrópolis: Vozes.

(1988). Presente e Futuro. Petrópolis: Vozes.

LAYRARGUES, Philippe Pomier. (2004). Identidades da educação ambiental brasileira. Brasília: Ministério do Meio Ambiente.

NEUMANN, Erich. (1999). A Grande Mãe: Um estudo fenomenológico da constituição feminina do inconsciente. São Paulo: Cultrix.

NAESS, Arne. (1973). The Shallow and the Deep, Long-Range Ecology Movement: A Summary. Inquiry: An Interdisciplinary Journal of Philosophy/Routledge, London-UK, v.16, n.1: p.95-10o, jan/fev.

(1992). “The Three Great Movements”. The Trumpeter, Canada, v.9, n.2: p.01-05, mar/abr.

. (2001). Ecology, Community and Lifestyle: Outline of an ecosophy. London-UK:

Cambridge.

OLIVEIRA, Rosalira. (2005). "Em nome da Mãe: o arquétipo da Deusa e suas manifestações nos dias atuais”. Revista Ártemis, João Pessoa, v.5, n.3: p.o1-16, dez.

SEIXAS, Raul; COELHO, Paulo. (1974). Gita. In: Gita (album). LP Philips.

ZIMMERMAN, David. (1992). “Arne Naess, Celebrant of Diversity”. The Trumpeter, Canada, V.9, n.2, p.o1-05, mar-abr.

Recebido: 09.10.2017

Aceito: 29.06.2018 